\title{
11. TIME, POWER AND THE EMANCIPATORY AIMS OF ADULT EDUCATION
}

\author{
INTRODUCTION
}

\section{Adult Education and the Fluidity of Power Dynamics}

In Western societies, the experience of time has probably never been as ordered, controlled and disciplined than it is today. It appears in adult education through the rigidity imposed on schedules and planning, or through the age requirements defined by educational policies. At the same time, the temporalities of adult life are more often experienced as discontinuous, troubled and chaotic than before. Nowadays, the evolution of adulthood is characterized by the destandardization of the life course, the heterogeneous rhythms that divide the everyday life (e.g., family, work, studies), or the frequency of organizational and technological changes disrupting daily routines. The effects of such dynamics have become more intense, influenced by the preponderance of 'speed'. Thus, rigid temporal frameworks, coupled with a sense of urgency lead to the experience of stress, burnout or the compulsive repetition of monotonous behaviors. As time scarcity and the acceleration of learning invade the everyday practice of adult education (e.g., Plumb, 1999; Wlodkowski, 2003), they jeopardize the possibility to exercise sound judgment and critical reflection. With the compression of temporal perspectives to the immediate present, they make it more difficult for people to revisit their past, anticipate their future, or assert their own rhythms of development. If the influences of temporal constraints have a long history in education (Alhadeff-Jones, 2017), their current configurations express something significant about how power dynamics and alienation may be experienced. They reveal social inequalities in the way adults experience time and their struggle to articulate the competing rhythms that pace their lives. They also raise questions about how people learn to sustain the development of their autonomy through time and how they regulate their sense of agency when facing conflicting temporalities.

Considering such a context, the purpose of this chapter is to revisit emancipation and the democratic ideals of adult education, questioning their temporal dimensions. This reflection assumes that the temporal features of the environment we are living in, and the rhythms that currently shape both adulthood and adult education should become a focus of critical inquiry and praxis. One of the specificities of this contribution is that it assumes simultaneously the social and political nature of this 
topic, as well as its physical, biological, psychological and philosophical dimensions. The experience of time relates to heterogeneous forms of change, occurring at the different levels of one's existence. From an educational perspective, the relation between time and emancipation carries an epistemic complexity. Echoing a long tradition of interdisciplinary research around human rhythms and their political dimensions (e.g., Alhadeff-Jones, 2017; Bachelard, 1950; Barthes, 2002/2012; Lefebvre, 2004; Michon, 2005), and inspired by original contributions developed in the French-speaking field of adult education (e.g., Ardoino, 2000; Pineau, 1986, 2000; Lesourd, 2006), this chapter intends therefore to demonstrate both the relevance of reinterpreting emancipatory processes, focusing on the fluidity of power dynamics, and the specificity of analyzing their rhythms from the perspective of adult education (Alhadeff-Jones, 2017).

\section{Four Postulates to Envision the Complex Relations between Time and Emancipation in Adult Education}

To envision how the exercise of power relates to the experience of time and how they affect the complexity of adult learning and development, the reflection conducted in this chapter formulates four postulates. (i) The first one relies on the assumption that the exercise of power always relates to the experience of natural and cultural temporal constraints. To understand how power dynamics unfold and how they affect the praxis of adult education, it is therefore critical to analyze the emergence of successive, concomitant and intertwined strategies implemented to control those temporal constraints. (ii) A second postulate assumes that a cultural shift has marked late modernity and currently affects the way people experience and struggle with the temporalities of their life, including their experience of lifelong learning. To describe and interpret such disempowering experiences, the notions of 'temporal alienation' and 'schizochrony' are introduced. (iii) A third postulate claims that the aim of emancipatory education should be envisioned through the development of a critical capacity to interpret and challenge the way time is experienced and meanings are constructed around it. (iv) The fourth postulate is to conceive emancipation in itself as a phenomenon that unfolds through time and that reveals the idiosyncrasy of one's own development. Emancipatory education relates to people's capacity to regulate the ever-evolving dynamics between autonomy and dependence; it expresses the rhythms through which adults change, grow and transform themselves throughout their lives. This chapter finally proposes to envision further critical development in adult education through the lenses provided by rhythm studies and rhythmanalysis - a dedicated method focusing on the study of lived rhythms - as they may provide resources to imagine innovative educational praxis focusing on the experience of time in the everyday life and throughout the life course. 
TIME, POWER AND THE EMANCIPATORY AIMS OF ADULT EDUCATION

\section{QUESTIONING THE SOCIAL REGULATION OF TEMPORAL CONSTRAINTS}

\section{The Ubiquity of Temporal Constraints}

Like social and cultural life, education is determined by physical and living phenomena - whether natural or artificial - whose rhythms influence people's behaviors and interactions. Chronobiologists and chronopsychologists have for instance demonstrated how learning activity is regulated by biological and psychological rhythms that are partly determined genetically (e.g., sleep cycle, attention span) (Koukkari \& Sothern, 2006; Testu, 2008). Cosmological and ecological rhythms (e.g., circadian rhythm, cycle of seasons) also impact human activity, through the influence of physical, chemical and biological changes that occur in the environment and that follow their own temporalities. Such phenomena are examples of natural rhythmic influences. Temporal constraints confine, bound, restrict or put into tension the operations involved by human activity, including in education, where they eventually influence the temporalities of individual and collective learning, transformation or development (Alhadeff-Jones, 2017, pp. 51-52). Although they do not manifest power or control per se, the way such temporal constraints are regulated is a matter of power dynamics.

\section{Time and Power}

How a society defines and controls time is at the core of the way it exercises power (e.g., Adam, 1994; Attali, 1982; Bergmann, 1992; Foucault, 1975/1995; Thompson, 1967). Thus, the primary function of those in power is to give meaning to the multiple times of the world, to name them and to organize collective life based on their rhythms (Attali, 1982, p. 13). As summarized by Bergmann (1992, p. 99):

Time's ordering character for social life does not arise from the passage of time or the temporal duration of social systems, but from its normative effect on the structure and coordination of behaviour.

For Adam (1994, p. 107):

As long as we remain part of a society that is structured to the time of clocks and calendars our activities and interaction with others can only escape its pervasive hold to a very limited extent.

Thus, even when human activities are not explicitly referring to the time of clocks and calendars, the constant processes of adjustment that occur between people consciously or not - translate rhythmic forms of influence that eventually express power dynamics (Michon, 2005). In adult education, such dynamics appear clearly through the experience of temporal pressure, that is the imposition of a specific rhythm to one's activity, due to social, economic or political reasons. Such a pressure appears for instance through the implementation of 'accelerated learning' 
in higher education (Wlodkowski, 2003), privileging economical imperatives over pedagogical considerations.

\section{Temporal Discipline, Temporal Norms and the Disorganization of Lived Time}

The history of education is characterized by the emergence of successive, concomitant and intertwined strategies implemented to control existing temporal constraints, such as those inherent to the natural world and the human body. Those strategies of control have produced specific forms of temporal constraints that are social and cultural. They reveal conflicting principles, interests and ideals (e.g., temporal efficiency, rhythmic harmony) (Alhadeff-Jones, 2017). Their most prevalent forms appear through the temporalities that organize institutions, such as education. On the one hand, the way they participate in the exercise of power is functional. For instance, the implementation of temporal discipline reduces individual's margins of autonomy through the imposition of fixed schedules, sequences of actions, or the influence of specific rhythms, in order to regulate what would be otherwise perceived as asynchronous, unpredictable or uncontrollable behaviors (e.g., Zerubavel, 1981). On the other hand, social forms of temporal constraints also operate at the symbolic level. The influence of specific representations (e.g., clocks, calendar) binds the social imaginary of time by reducing it to an abstract, quantified, linear, and universal conception. Its dominance may thus limit how the everyday experience of change is appreciated and interpreted (Ardoino, 2000). In the same way, the definition of age norms (e.g., legitimate entry and exit points relative to formal instruction) reinforces temporal standards that influence the way life trajectories are experienced and appreciated. Constraints associated with the shared experience of time do not necessarily come from the imposition of a temporal order. They also appear through the experience of disorganized temporalities. Thus, the increased confusion and disorder inherent to conflicting temporal demands (e.g., family versus working life), as well as the fragmentation and the discontinuities that punctuate the life course (e.g., unemployment, sickness), emerge as disorganizing factors. They tend to increase uncertainty and instability and constitute disempowering experiences that may prevent one from developing a genuine sense of autonomy (Alhadeff-Jones, 2017; Pineau, 2000).

\section{CONSIDERING THE CONTEMPORARY EXPERIENCE OF TEMPORAL ALIENATION}

\section{Defining Temporal Alienation}

The concept of alienation has been used in social theory to evoke "a loss, a severance from a part that becomes alien, as well as to the independent power that such a lost part acquires over one's own existence" (Martineau, 2015, p. 14). For Marx (1847/1955), working time required in order to produce merchandise is alienating, 
partly because it is based on an abstract estimate, opposed to the concrete time experienced by workers. The rationalization of work contributes to the reification of time, which loses its qualitative, changing, and flowing attributes and becomes rigid, delimited, quantified and objectified, according to a mechanical logic, detached from the subjective experience (Lukacs, 1960, cited in Pineau, 2000). Furthermore, working time is alienating because it determines and constrains individual actions (Postone, 1993, p. 215). The tyranny of time in capitalist society remains therefore a central dimension of Marxian analysis and a recurring theme in sociological studies focusing on the role played by the rigidity, the coercion and the regularity imposed through the temporal framework of industrialization (e.g., Adam, 1994).

\section{The New Temporal Imperatives: Speed, Urgency, Acceleration}

During the past decades, many authors have revisited this problematic, exploring the effects of temporal alienation through specific notions such as 'speed' (e.g., Hassan, 2009; Virilio, 1977), 'urgency' (e.g., Bouton, 2013), and the 'acceleration' of the everyday life (e.g., Rosa, 2005/2013). Doing so, they provide us with interpretations to grasp the cultural shift that seems to have marked late modernity and currently affects people's experience and struggles with time. Nowadays, conflicts associated with the experience of time (e.g., stress, burnout, lack of workfamily balance, monotonous or compulsive repetitive behaviors) express renewed forms of temporal constraints that reveal underlying power dynamics and conflicts of interest. Research is needed in order to critically assess such contributions and discuss how their commonalities and divergences may be articulated. Not everyone is indeed equally equipped to cope with temporal tensions. Gendered inequalities and differences related to class, ethnicity, or age, have to be considered in order to fully grasp the extent to which temporal alienation is experienced. It remains that such an evolution impacts educational practices and determines the way adults regulate the temporalities of their lives and the rhythms of their own development.

\section{Adult Education and the Experience of Schizochrony}

In the field of adult education, Pineau (1986, 2000) was among the first to start reflecting on the meaning of éducation permanente, as it relates to people's experience of temporal alienation. He proposed the neologism 'schizochrony' (from the Greek schizo-, meaning divide, and chronos, time) to refer to the various forms of temporal divide that may be experienced and eventually lead individuals to the feeling of being temporally alienated throughout their life, including in the way they relate to their own self-development. Such splits occur for instance between the qualitative aspects of lived time (e.g., the feeling of flow) and the social necessity to remain temporally oriented and therefore quantify and measure one's time (e.g., checking the hour or the date). For Pineau (1986, p. 100), the alienating dimension of the temporal frame imposed by society is omnipresent in the temporal organization of adult education. 
Its homogeneous and homogenizing aspects, the monotony of the 'mechanical succession' of days, weeks, months and years, all erase the qualitative differences of lived moments, that could be experienced as heterogeneous opportunities for self-development. If traditional educational theories conceive learning time as uniform and homogeneous (e.g., the course's hour, the daylong training), Pineau's contribution challenges the way they compartmentalize learning and the various meanings it carries. It stresses for instance the role played by alternative temporal patterns, such as the alternance between day and night: "Just as the day is the realm of an education received from others [hétéro-formation], the nocturnal realm is that of self-development [auto-formation]" (Pineau, 2000, p. 105). Once it is no longer kept separated and lived as if it were strictly free and private, nighttime - including dusk, end-of-the-day transition, evening, dreaming, waking time, sleeplessness and dawn time - provides indeed a privileged moment for the emergence and development of one's own autonomy. By discussing the formative dimension of the 'nocturnal' component of existence, Pineau finally stresses the fact that being able to establish relations between the different moments of one's life carries emancipatory effects.

\section{AIMING AT THE APPROPRIATION OF ONE'S OWN TIME}

\section{Articulating Heterogeneous Experiences and Conceptions of Time}

One of the common features identified by authors referring to the idea of temporal alienation appears with the disconnection, the 'distorsion' (Rosa, 2010) or the 'decoupling' (Thompson, 1967), that occurs between the 'qualitative' time experienced as meaningful by people, and the quantitative, standardized and abstract time imposed onto their activity, through social dynamics favoring speed, acceleration or the generalization of temporal norms such as urgency. According to Postone's (1993) reinterpretation of Marx's critical theory, one of the specificities of capitalism is that people are dominated by abstractions, rather than by other individuals or groups. Capitalism throws people into abstract time and work, that become the measure of everything (e.g., labor time as an objective temporal norm) (Postone, 1993, p. 215). From this perspective, what appears to be at stake is the individual and collective capacity to relate and articulate heterogeneous experiences and conceptions of time, especially as they may be conceived as disjointed, contradictory or antagonistic with each other. Rosa evokes Taylor's (2006, as cited in Rosa, 2010) idea of 'resonance' in order to envision an existentialist and emotional strategy of emancipation centered on the way people relate to the world around them. From an epistemic perspective, following Morin's ethic (2008), we could also refer to the notion of 'reliance', as a capacity to articulate ideas and experiences, which would remain otherwise disconnected, fragmented or compartmentalized (Alhadeff-Jones, 2017). In order to resist against the autonomization of an abstracted and generalized conception of time, that imposes itself onto people's life and contributes to a feeling of alienation, strategies of reliance should be found and promoted. They may for instance bring 
one to articulate different moments of the everyday life, as suggested by Pineau's reflections on the alternance between daytime and nighttime, as two antagonistic and complementary moments of one's own development. Such strategies should help people to relate and interpret the heterogeneous experiences and meanings of time that are constitutive of their life, including those lived as temporal constraints.

\section{Learning to Synchronize the Heterogeneous Rhythms of One's Life}

What is critical in such an emancipatory process is the capacity to organize heterogeneous experiences of time (e.g., linear, circular, quantitative, qualitative, fast, slow, internal, external, fixed, flowing, reversible, irreversible) as they emerge in different spheres of one's life. The term 'organization' does not refer here to the instrumental notion of 'time management' as a set of skills required in order to arrange one's commitments according to a schedule or a calendar. It rather refers to the ability to articulate meanings that translate complementary, contradictory and antagonistic experiences, such as those associated with the different moments of one's existence (e.g., education, work, family, leisure). In a context of temporal alienation, emancipatory education relies on the capacity to challenge the way time is experienced and meanings constructed around it (Alhadeff-Jones, 2017). Such a perspective is for instance found in adult education through practices that privilege the use of life history (e.g., Dominicé, 2000). Through their multiple expressions, such approaches assume the potential benefits inherent to the organizing effects, catalyzed by the production and the sharing of a life narrative. For Pineau (2000), what is critical is to bring adults to learn how to distribute, combine and balance the rhythms and times that compose the historicity of their lives to fight against the experience of schizochrony. Inspired by the work of Bachelard (1950) and Lefebvre (1992/2004) around the idea of 'rhythmanalysis', Pineau refers to the term 'rhythmoformation' to envision an educational praxis whose aim would be to support adults to develop themselves through the integration and the articulation of the plurality of biological, social and physical rhythms that compose their lives. Borrowing the concept of 'synchronization' from chronobiology, Pineau (2000) suggests that the appropriation of one's own time requires a process of adjustment, based on the capacity to synchronize the heterogeneous rhythms that constitute one's life. Accordingly, the emancipatory aim of adult education would require the capacity to take charge of the temporal conditions through which meanings emerge in everyday life, as well as through the life course (Alhadeff-Jones, 2017).

\section{CONCEIVING THE RHYTHMS OF EMANCIPATION}

\section{Defining Emancipation}

Emancipation literally means to give away ownership (ex: away; mancipum: ownership). More broadly it means to relinquish one's authority over someone. By 
extension, the term refers to the action of freeing or liberating (oneself) from a state of dependency, or the state that results from such an action. Emancipation is rooted in the refusal of an established order. It designates the opening of a space and time of rupture. It also constitutes an effort and a movement that reciprocally carries on the subject that exercises them (Navet, 2002). Any movements of emancipation aim at modifying fundamental relationships between humans, and affecting them by their very existence. Such a movement is linked to a critical moment through which the social and political organization of society appears through its arbitrary power and contingency (Navet, 2002). However, the meaning and the aim of emancipation can never be taken for granted. First, because the forms of dependence and power dynamics evolve constantly throughout history. Second, because emancipation is not a state that could be reached once for all. It should rather be conceived as a fluctuating process that evolves through time. It is therefore critical to envision it through the dynamics it encompasses.

\section{Conceiving the Temporal Complexity of an Emancipatory Process}

Morin (2008) proposes to conceive emancipation and alienation through their dialogical relationship. The 'autonomy-dependence' principle he formulates focuses on the property according to what makes a system self-sufficient and autonomous is also what makes it dependent. For instance, students who go deeply into debt to cover the cost of an academic degree potentially increase their autonomy, as they may get access to a larger number of professional opportunities over the long-term; at the same time, they also increase their financial dependence on their lenders, which therefore reduces their immediate margins of action. Accordingly, it appears as misleading to conceive freedom without reflecting on the constraints or dependency it involves. Morin's autonomy-dependence principle encourages one to systematically consider emancipatory processes through the complex interplay between complementary, contradictory and antagonistic forms of self and mutual control (e.g., exercised through symbols, discourses, bodies or social relations), rather than considering them as separated and mutually exclusive. The feeling of being emancipated fluctuates therefore, because it relies on the changing level of autonomy that people experience in different situations and at different periods of their life (Alhadeff-Jones, 2017). Considering the emancipatory aim of adult education, such considerations raise questions not so much related to the possibility to eradicate or dominate temporal constraints and power dynamics. They rather display the importance of being able to purposefully regulate the balance that may always exist between the experience of autonomy and dependence.

\section{Envisioning the Rhythms of Emancipation}

As a fluctuating process, emancipation, from this perspective, relies on both the experience of ruptures (e.g., ordeal, crisis, revolution) and what Jullien (2011) calls 
'silent transformation', that is unconscious ongoing dynamics of change which encompass multiple dimensions of one's existence. Michon (2005, p. 423) - who privileges the term "individuation" to describe processes of emancipation - stresses the fact that such a movement is neither static nor totally erratic. The dialogic between emancipation and alienation, autonomy and dependence, must therefore be conceived neither as fully ordered nor as fully disordered. It fluctuates through evolving forms - involving discourses, bodies, moods, social interactions organized through time. Such 'forms in movement' can be conceived as rhythmic, based on the etymology of the term 'rhuthmos' (Michon, 2005). In How to Live Together, Barthes (2002/2012) calls it 'idiorhythmy' in reference to the phenomena through which people aim at finding and following a particular (idios) rhythm and those experiences where individual freedom is understood as the conquest of one's own rhythm. Barthes' concept of idiorhythmy relates to the everyday life in a community, but the phenomena he refers to evolve throughout the life course and history. Every day, autonomy emerges as people regulate the way they express themselves, the way they move or interact with each other (Michon, 2005). The flow of those discursive, embodied and social configurations evolves and translates specific rhythms and temporalities through which people eventually develop individually and collectively - their autonomy throughout their existence. From that perspective, emancipatory education is not just about overcoming a feeling of temporal alienation. It also involves the capacity to sustain such a process over time, through one's own rhythms. Conceiving emancipation as a fluctuating and rhythmic process raises therefore new questions for adult educators about the ways people develop their capacity to regulate their sense of agency through time.

\section{TOWARD A RHYTHMANALYTICAL CONCEPTION OF ADULT EDUCATION}

Finding, asserting and sustaining the idiosyncratic rhythms through which people regulate the ever-evolving tensions between autonomy and dependence provides the field of adult education with a renewed interpretation of what could be its emancipatory aims, in a context of temporal alienation. Such a perspective opens up at least two paths of inquiry. Firstly, that we renew the educational praxis in order to take into consideration how people learn to critically assess and negotiate the complementary, antagonistic and contradictory rhythms that are constitutive of their life and the power dynamics that relate to them. It raises questions regarding how adults develop the capacity to discriminate, interpret, evaluate, argue, judge and eventually challenge the qualities of the temporalities through which they experience the everyday life. Secondly, that we study and foster the rhythms that shape how adults develop their sense of agency and sustain an emancipatory process over time. It raises questions regarding the patterns and the repetitions experienced throughout the adult life that are constitutive of the temporality of such a movement. It also questions how to describe and influence the flow of experience through which people constantly regulate autonomy and dependence in adulthood. 
Continued clarification and development of additional resources to analyze, interpret and assess the temporalities involved in adult education and the way they contribute to alienate and/or emancipate learners and educators as well is required. The reflection briefly developed in this chapter should be conceived as a starting point. Envisioning a rhythmanalytical approach to adult education may lead to the development of innovative praxis aiming explicitly at uncovering the rhythms that determine and shape how adults learn, transform and develop themselves in the different spheres of their lives. In the contemporary context, it seems particularly relevant - and urgent - to pursue such an aim.

\section{REFERENCES}

Adam, B. (1994). Time and social theory. Cambridge: Polity Press.

Alhadeff-Jones, M. (2017). Time and the rhythms of emancipatory education. Rethinking the temporal complexity of self and society. London: Routledge.

Ardoino, J. (2000). Les avatars de l'éducation. Paris: Presses Universitaires de France.

Attali, J. (1982). Histoires du temps. Paris: Fayard.

Bachelard, G. (1950). La dialectique de la durée. Paris: Presses Universitaires de France.

Barthes, R. (2012). How to live together: Novelistic simulations of some everyday spaces (K. Briggs, Trans.). New York, NY: Columbia University Press. (Original work published in 2002)

Bergmann, W. (1992). The problem of time in sociology: An overview of the literature on the state of theory and research on the 'sociology of time', 1900-1982. Time \& Society, 1(1), 81-134.

Bouton, C. (2013). Le temps de l'urgence. Lormont, France: Le Bord de l'eau.

Dominicé, P. (2000). Learning from our lives: Using educational biographies with adults. San Francisco, CA: Jossey-Bass.

Foucault, M. (1995). Discipline and punish: The birth of the prison (A. Sheridan, Trans.). New York, NY: Vintage Book. (Original work published in 1975)

Hassan, R. (2009). Empires of speed: Time and the acceleration of politics and society. Leiden: Brill.

Jullien, F. (2011). The silent transformations (K. Fijałkowski \& M. Richardson, Trans.). Chicago, IL: Seagull Press.

Lefebvre, H. (2004). Rhythmanalysis: Space, time and everyday life (S. Elden \& G. Moore, Trans.). London: Continuum. (Original work published in 1992)

Lesourd, F. (2006). Des temporalités éducatives: Note de synthèse. Pratiques de Formation/Analyses, $51-52,9-72$.

Koukkari, W. L., \& Sothern, R. B. (2006). Introducing biological rhythms. New York, NY: Springer.

Martineau, J. (2015). Time, capitalism and alienation: A socio-historical inquiry into the making of modern time. Boston, MA: Brill.

Marx, K. (1955). The Poverty of philosophy (Institute of Marxism-Leninism, Trans.). Moscow: Progress Publishers. (Original work published in 1847)

Michon, P. (2005). Rythmes, pouvoir, mondialisation. Paris: Presses Universitaires de France.

Morin, E. (2008). La méthode. Paris: Seuil. (Original work published in 1977-2004)

Navet, G. (Eds.). (2002). L'émancipation. Paris: L'Harmattan.

Pineau, G. (1986). Time and lifelong education. In P. Lengrand (Ed.), Areas of learning basic to lifelong education (pp. 95-120). Oxford: UNESCO Institute for Education (Hamburg) \& Pergamon Press.

Pineau, G. (2000). Temporalités en formation. Paris: Anthropos.

Plumb, D. (1999). Adult education in a world 'on speed'. Studies in Continuing Education, 21(2), 141-161.

Postone, M. (1993). Time, labor and social domination: A reinterpretation of Marx's critical theory. Cambridge: Cambridge University Press.

Rosa, H. (2010). Alienation and acceleration: Towards a critical theory of late-modern temporality. Svanesund: Nordic Summer University Press. 
TIME, POWER AND THE EMANCIPATORY AIMS OF ADULT EDUCATION

Rosa, H. (2013). Social acceleration: A new theory of modernity (J. Trejo-Mathys, Trans.). New York, NY: Columbia University Press. (Original work published in 2005)

Testu, F. (2008). Rythmes de vie et rythmes scolaires. Issy-les-Moulineaux: Masson.

Thompson, E. P. (1967). Time, work-discipline and industrial capitalism. Past and Present, 38, 56-97.

Virilio, P. (1977). Speed and politics. Los Angeles, CA: Semiotext(e).

Wlodkowski, R. J. (2003). Accelerated learning in colleges and universities. New Directions for Adult and Continuing Education, 97, 5-15.

Zerubavel, E. (1981). Hidden rhythms: Schedules and calendars in social life. Berkeley, CA: University of California Press. 